\title{
The Impact of Employee Satisfaction on Innovation Capacity in Telecommunications
}

\author{
Anes Hrnjic \\ University of Sarajevo, Bosnia and Herzegovina \\ Irma Djidelija \\ University Dzemal Bijedic, Mostar, Bosnia and Herzegovina
}

\section{Abstract}

The dominant feature of today's business environment is accelerated dynamics and dramatic change intensity which significantly influences the life cycle of strategy, business orientation and individual employee operations. These trends require continuous adjustment of business philosophy through innovation in various contexts acting as key drivers for successful handling of change and implementation of innovative ideas. Recent research shows that $39.9 \%$ of employed citizens within EU operate in the services sector while it accounts for $46.2 \%$ of added value creation in the EU market. Telecommunications are one of the major segments of services sector and people working for telecom operators represent the crucial asset in innovation management in the particular industry. Organizational behavior in terms of innovation is determined by various factors, whose number, direction and intensity is not yet clearly defined. Research aims to explore the impact of job satisfaction on innovative capacity of telecom operators in Bosnia and Herzegovina evaluating efficacy of HRM (human resource management) practices in the process of creating and implementing innovation. Methodology consists of two appropriate instruments for evaluation of job satisfaction and employee innovative behavior and primary data was analyzed using linear regression method. Limitations of the study are discussed and recommendations for future research of job satisfaction impact on employee innovative behavior are given. Practical implications on how to stimulate innovation in the organizational context are states in the discussion and conclusion.

Keywords: employee satisfaction, innovation, telecommunications, HRM JEL classification: L96, J28, O30

\section{Introduction}

In the contemporary business environment, life expectancy of strategy is reduced. Hence, innovation has become the only mean by which companies can extend their success due to an extremely high degree of competition in different sectors of economy, especially in the services sector such as telecommunications. In previous decades, many businesses were quite isolated from the rivalry within the industry as well as the potential competition entry due to various factors. The supreme factors that have protected industry leaders from the competition include regulatory barriers, distribution monopolies, a weak bargaining power of consumers, proprietary standards, economies of scale and others (Rahimic et al., 2013). However, today these factors responsible for privileged status of the most dominant companies collapsed as a result of deregulation and liberalization of markets, the emergence of new communication channels such as the Internet, degradation of many large companies through outsourcing activities, appearance of informed and well educated customers who have much higher negotiating power and so on. 
Therefore, innovation became imperative for companies that aim to be competitive in today's modified and highly dynamic business environment. Therefore, currently employees are seen as key drivers of change which have an essential role in the creation of innovation (Hamel, 2007).

Increasing competition, rapid globalization and development of IT have resulted in the emergence of business concepts with a focus on customer satisfaction. In fact, previous studies show that it is five to six times more expensive to acquire a new customer than to retain an existing (Keiningham et al., 2005). Hence, companies have realized that closely related to the achievement of great customer satisfaction is high level of job satisfaction among employees who are often appointed by term internal customers (Mahmood et al., 2014). Job satisfaction can be defined as employees' positive emotional state and attitude which is accomplished through work experience and benefits of successfully performing tasks (Locke, 1976). Executive focus on the labor market and managerial commitment to considering needs and values of employees attempting to fulfill them is represented by term internal market orientation (Yoon et al., 2004). Recent HRM research highlights that psychological empowerment of employees has great importance for present organization as a result of dynamic changes in the commercial ambient (Allameh et al., 2012). Psychological empowerment is not only seen as delegating to employees who are hierarchically below top management, but is imparted to employees' psychological well-being affecting their emotional state as well (Conger et al., 1988).

Also, Spreitzer et al. (1997) believe that the concept of employee psychological empowerment is wide and empowerment in that context can be defined as a psychological state or cognitive processes that are based on personal experiences within companies and employees' perception of business processes. Psychological empowerment affects a wide range of outcomes in organizational context such as the intention to leave the organization, appropriate and desirable organizational behavior, business performance, organizational learning, creativity of employees, job satisfaction, etc. (Singh et al., 2013) . Key factors influencing job satisfaction can be classified into six categories: opportunities for development, stress caused by job activities, superiors' leadership skills, labor standards, adequacy of reward or compensation system and authority/responsibility (Odzemir, 2009). Companies in which innovation is defined as a key competence are able to produce and deliver superior products or services in which strategic competitive advantage is achieved through exploitation of employees' ability to generate new ideas who are at the same time knowledgeable and creative (Jafri, 2010).

Cummings et al. (2005) define innovation as the successful implementation of creative ideas, tasks or processes. On the other hand, De Jong et al. (2007) define innovative behavior as behavior aimed at initiating and implementing new ideas, products, processes and their connection with business performance, groups or organizations. Scott et al. (1994) point out that innovation is an iterative process and that each new level requires different activities and individual behavior in which the innovation is formulated on the basis of discontinuous, non-sequential operations. Thus, the key characteristics of innovation are: novelty, intentionality of benefits and innovation process (West et al., 1996). Previous studies in the field of innovation management in different sectors have shown that the process of innovation is determined by various factors, but the number, direction and intensity of these factors is not clearly defined. Weeks et al. (2011) explored the relationship between innovation, the ability to absorb knowledge and practices of human resource management. Results showed that the HRM has a direct impact on the level of knowledge absorption capacity and development of innovations. 
The new position of the services sector in the economy has led to an increase in innovation, competition, employment and economic growth (Howells et al., 2004). Various studies in the European Union have shown that in the year of 2004, more than one third (precisely 39.9\%) of employees were in the services sector and this particular sector created $46.2 \%$ of added value (Arundel et al., 2007). The growing role of the services sector imposes the need for analysis of the determinants of innovation, which provided a positive trend of market development. This research has an objective to explore the impact of job satisfaction on innovative capacity of telecom operators in Bosnia and Herzegovina evaluating efficacy of HRM practices in the process of creating and implementing innovation. The paper structure includes a literature review presented in the introduction following detailed explanation of methodology applied, presentation of results obtained based on the collected primary data and, in the end, research results are discussed in terms of practical implications, limitations and recommendations for upcoming/future studies followed by conclusions and list of references used.

\section{Methodology}

In the literature, often we find that customers are the central stakeholder, but in today's turbulent environment many HRM specialists consider that employees are the most important participant within the economy market because businesses cannot successfully complete their goals and deliver a top quality product or service if their employees are not satisfied or motivated. In order to achieve research goals, the survey was conducted on a random sample of 116 respondents who are employed in the telecommunications sector. Online questionnaire consisted of 33 questions that are related to different segments of job satisfaction described in the literature review such as independence of decision-making, opportunities to perform variety of tasks and to influence other coworkers, supervisors' leadership skills, ethical standards, job security, adequacy of compensation, promotion in line with the education/performances, interpersonal relations as well as issues related to the possibility of manifestation of the innovative behavior (use of new working methods, techniques and instruments, finding original solutions to current problems, new approaches to business tasks, transference of enthusiasm in the process of innovation, systematic continuity of the presentation of new ideas, the development of new technologies, etc.) and, in the end the questionnaire, demographic profile including gender, age and education level of respondents.

The questionnaire was created by combining two standard instruments used in scientific research designed to examine the employees' job satisfaction and the manifestation of innovative behavior in corporate environment. Minnesota questionnaire was applied in order to determine the level of job satisfaction (a short version consisting of 20 questions) and the other is Scott-Bruce survey form for determining the degree to which employees have the opportunity to express innovative behavior in the organizational context. Gender-wise, demographic profile includes 55 employees (or $47.41 \%$ ) who are women and 61 respondents who are male (or $52.59 \%$ ). Almost the half of respondents, precisely 48 (or $41.38 \%$ ), belongs to the age group 26-36, followed by 39 respondents in the age group $36-45$ (or $33.62 \%$ ). The least number of respondents are from the youngest category of employees who aged 25 years old or younger (14 employees or 12.07\%), which is understandable if we take in consideration that the number of unemployed young people in Bosnia and Herzegovina is above $40 \%$. It should be noted that the majority of respondents completed undergraduate studies, precisely $47.41 \%$. Also, $32.76 \%$ have completed some sort of post-graduate studies (master or doctoral studies). High level of well- 
educated employees can be argued by the type of sector in which the sample was collected because it is high-tech sector which is characterized by a great degree of organizational professionalism (the level of the highly educated workers).

The calculation of a priori statistical power at level 1 with a mean level of size effects (0.15) and a confidence level of $a=0.05$ was used to determine the sample size. The high statistical power reduces the probability of making a Type II error. Selected level of statistical power produces statistically significant results each time. All questions in an online survey form were mandatory, so there were no missing data. Given that the dependent and independent variables are both ordinal, linear regression was used. Prior to the application of the method, it was investigated whether they met the statistical assumptions for its application (normality, linearity, heteroscedasticity). For the purposes of this analysis, eleven regression models were created. Ten models represent the individual analysis of dependent variables related to measurements of innovative behavior. The eleventh regression model included a summary dependent variable for which we previously tested the possibility of its formation using the Cronbach's alpha test of reliability. All statistical calculations were performed using the software package SPSS.

\section{Results}

Statistical characteristics of variables resulted in the application of linear regression method as stated in the methodology and defined hypotheses of the paper was rephrased, for the purposes of statistical analysis, to the following form: There is a statistically significant correlation between employee job satisfaction and their expression of innovative behavior in daily tasks in the telecommunications sector. According to the methodological framework, the measurement of innovative behavior (using data obtained by ten survey questions concerning the expression of innovative behavior in corporate environment of telecommunication operators), presented basis for developing ten regression models. The statistical assumptions for the application of regression analysis are met in each individual model and assumptions are tested via appropriate graphic representations such as histogram, normal $\mathrm{p}-\mathrm{p}$ plot and scatter plot). All ten models, at the level of reliability of $1 \%$, showed a significant correlation between the innovative behavior and job satisfaction through obtained correlation and regression coefficients. Hence, significant variability in the occurrence of innovative behavior can be explained by job satisfaction (the value of the coefficient of determination).

In further steps of research, the possibility of summarizing measures of innovative behavior in an average variable using Cronbach's alpha test was checked. The value of Cronbach's alpha test of reliability on the level of 0.902 , confirmed the possibility of creating an average of the dependent variable, which was then used in the eleventh regression model (shown in the Table 1 below). 


\section{Table 1}

Representation of the $11^{\text {th }}$ regression model

a) Correlation and determination coefficients

\begin{tabular}{|c|c|c|c|c|c|c|c|c|c|}
\hline \multirow{2}{*}{ Model } & \multirow{2}{*}{} & \multirow{2}{*}{$\begin{array}{c}\mathbf{R} \\
\text { Square }\end{array}$} & $\begin{array}{c}\text { Adjusted } \\
\mathbf{R} \text { Square }\end{array}$ & $\begin{array}{c}\text { Std. Error } \\
\text { of the } \\
\text { Estimate }\end{array}$ & $\begin{array}{c}\mathbf{R} \\
\text { Square } \\
\text { Change }\end{array}$ & $\begin{array}{c}\mathbf{F} \\
\text { Change }\end{array}$ & df1 & df2 & $\begin{array}{c}\text { Sig. } \mathbf{F} \\
\text { Change }\end{array}$ \\
\hline $\mathbf{1}$ & $.746^{a}$ &, 557 &, 463 &, 44851 &, 557 & 5,962 & 20 & 95 &, 000 \\
\hline
\end{tabular}

Note: $* 10 \%, * * 5 \%, * * * 1 \%$

b) ANOVA

\begin{tabular}{|c|c|c|c|c|c|c|}
\hline & Model & $\begin{array}{l}\text { Sum of } \\
\text { Squares }\end{array}$ & df & $\begin{array}{l}\text { Mean } \\
\text { Square }\end{array}$ & $\mathbf{F}$ & Sig. \\
\hline \multirow{3}{*}{1} & Regression & 23,984 & 20 & 1,199 & 5,962 & $.000^{* * *}$ \\
\hline & Residual & 19,110 & 95 & 201 & & \\
\hline & Total & 43,094 & 115 & & & \\
\hline
\end{tabular}

Note: $* 10 \%, * * 5 \%, * * * 1 \%$

Source: Authors

Based on the results obtained from creation of eleventh regression model, it can be concluded that there is a positive, high correlation between innovative behavior and job satisfaction (0.746). Further, analysis showed that job satisfaction explained $55.7 \%$ of the variability of innovative behavior and the model is statistically significant at $1 \%$ confidence level ( $p$-value $=0.000)$. According to the results of the last model, the manifestation of innovative behavior in corporate environment by employees in the sector of telecommunication services in Bosnia and Herzegovina, on average, are most affected by following factors: preoccupation and dedication to business assignments, the opportunity to participate in and conduct different types of tasks, supervisor' leadership competence and decision-making skills, performing tasks that are in accordance with employees' own value system and ethical/moral standards, guarantees related to job security in the future, possessing the necessary authority for personal assessment and action, the possibility of instructing other coworkers on how to deliver daily assignments and the company's ability to successfully implement internal procedures/rules in an everyday business practice. Employees will more likely express innovative behavior if they are well-informed about the basic and additional work assignments which also fit their personal system of values/ethical standards. Further, if employees have the authority to make necessary decisions on their own as well as to instruct other colleagues in their business actions and if they are safe in terms of employment in the long run, it is more likely that the manifestation of some sort of innovative behavior will occur in their daily operations. Results of regression analysis showed that job satisfaction is expressed through compliance of challenging tasks, management quality and working conditions, corporate culture, adequate compensation as well as the level of professional competence and knowledge.

\section{Discussion}

Study has showed that opportunities for further development will increase employee job engagement and consequently innovative behavior. Hence, development 
opportunities should be in line with the performance and results of employees, which should also be a solid ground for planning of training activities within the company aiming to enhance specific skills that are necessary to successfully perform daily job assignments. Employees will express greater satisfaction with their job if they have the opportunity to participate in various projects. Tasks that are in accordance with employees' own value systems as well as pleasant working conditions are important in manifestation of creativity within company. Work-related stress causes various disturbances to employees. Therefore, it is reasonable to address these job issues that cause stress in order to develop a more effective HRM practices (Lucanin, 2014). For example, stress can be related to the activities of others in the work environment and if the employee does not have adequate support of colleagues in his or her business activities, very often the situation leads to the appearance of job dissatisfaction resulting in less innovative behavior.

Results also confirm that employees prefer to work with superiors who have solid leadership skills and invest extra effort to motivate their subordinates to achieve better job performance. If the chief of staff is a person who does not care about his followers and do not devote enough time and energy to talk to his or hers coworkers aiming to increase motivation, employees may become unhappy with the assigned job. One of the crucial aspects of studying the relationship between leaders and followers and its impact on the job satisfaction and innovation is linked to the building of trust (Straiter, 2005). Companies that want to achieve a great level of employee satisfaction need to consider non-material motivation mechanisms. HRM specialists suggest that non-material incentives more appropriately address the needs of a higher order according to Herzberg hierarchy such as self-confirmation, autonomy of decision-making, respect of coworkers and others (Rahimic, 2010). Although assigning responsibilities and gaining authority is not the only element of psychological empowerment concept, study results confirm its significance in achieving greater employees' job satisfaction because more work authority and responsibility usually results in a higher degree of employee satisfaction leading to more likely expression of innovation in working methods, techniques and solutions.

\section{Conclusion}

Results of the overall regression analysis showed that job satisfaction expressed through compliance of challenging tasks, management quality, working conditions, corporate culture and climate within the organization, the type of compensation and rewards amount as well as level of professional competence and knowledge significantly increases the innovative behavior of workers in the process of creating novel methods, techniques and instruments of labor or finding original solutions for on-going issues and changes in the business environment. Thus, calculated values of the coefficients within constructed models confirm the research hypothesis, which states that job satisfaction has a positive influence on innovative behavior of employees and improvement in work tasks. For example, if a supervisor does not have the necessary competence to successfully run a business unit or internal rules and procedure in the organization are not implemented on a daily basis, then the employees who are knowledgeable, creative, and possess the necessary authority to self-act according to their conscience are more likely to find innovative solutions enabling the survival and progress of the company in the market.

Further development of the telecommunications sector will depend on the global market liberalization, so new technologies and competition positively affect the quality of services (Pejic-Bach et al., 2013). Hence, it is important to improve HRM practices in order to obtain adequate knowledge and competencies required for 
successful operations. Previous research in HRM and its impact on innovative capacity of the company came to similar conclusions. The evidence was found that increased job satisfaction as well as the emotional and psychological fulfillment of employees who are engaging in specific work positions within organizations has a positive impact on performance (Santos-Vijande et al., 2007; Swink et al., 2000). Only companies that have exceptional workers within its structure in terms of their knowledge, professional competency and creativity will be able to produce outstanding service quality as well as innovative solutions.

The practical implications for managers and HR specialists in telecommunications for developing more effective HRM practices highlight the recommendation of strategy of innovation based on the creativity and engagement of employees. Therefore, a key task of HRM as well as top management should be focused on creating conditions that encourage creativity. Also, innovation and creativity require continuous investment in people by expanding their space and freedom of action, allowing participation in decision-making and organization democratization, establishing collegial relations and partnership, enhancing coworker cooperation, valuing teamwork, diversity of tasks and long-term orientation. Finally, it is important to point out the limitations of the study in terms of the validity of results. Since previous studies have proved that differences in national cultures also to some extent affect employees' behavior (Chen, 2001; Trompenaars et al., 1998; Hofstede, 1991), future research on the subject matter should take into account the possible impact of national culture on business behavior or collect a sample from several countries in order to overcome the possibility of cross-cultural errors in interpreting the results.

\section{References}

1. Allameh, S.M., Heydari, M., Davoodi, S.M.R. (2012), „Studying the relationship between transformational leadership and psychological empowerment of teachers in Abade Township", Procedia-Social and Behavioral Sciences, Vol. 31, pp. 224-230.

2. Arundel, A., Kanerva, M., Cruysen, A. \& Hollanders, H. (2007), "Innovation statistics for the European service sector", report, Brussels, Belgium: European Commission, DG Enterprise.

3. Chen, M. (2001), „Asian Management Systems", Thomson, London.

4. Conger, J.A., Kanungo, R.N. (1988), "The empowerment process: Integrating theory and practice", The Academy of Management Review, Vol. 13 No. 3, pp. 471-482.

5. Cummings, J.N., Kiesler, S. (2005), "Collaborative research across disciplinary and organizational boundaries", Social Studies of Science, Vol. 35 No. 5, pp. 703-722.

6. De Jong, J.P.J., Den Hartog, D.N. (2007), „How leaders influence employees' innovative behaviour", European Journal of Innovation Management, Vol. 10 No. 1, pp. 41-64.

7. Hamel, G. (2007), "The future of managment", Boston: Harvard Business School Press.

8. Hofstede, G. (1991), "Culture and Organizations: Software of the Mind", McGraw-Hill, NY.

9. Howells, J., Tether, B. (2004), "Innovation in services: Issues at stake and trends", report, Brussels, Belgium: Commission of the European Communities.

10.Jafri, M.H. (2010), "Organizational commitment and employee's innovative behavior", Journal of Management Research, Vol. 10 No. 1, pp. 62-68.

11.Keiningham, T.L., Vavra, T.G., Aksoy, L., Wallard, H. (2005), „Loyality myths: hyped strategies that will put you out of business \& proven tactics that really work", John Wiley\&Sons.

12.Locke, E.A. (1976), "The nature and causes of job satisfaction", in M.D. Dunnette (Ed.), Handbook of industrial and organizational psychology, Chicago, Rand-McNally.

13.Lucanin, D. (2014), "Mjere prevencije i sprecavanja stetnih posljedica stresa" [Measures for the prevention of harmful effects of stress], izlaganje sa skupa, Sigurnost, Vol. 56 No. 3, pp. 223-234.

14.Mahmood, S., Attiq, S., Azam, R. (2014), "Motivational needs, core-self-evaluations and their link with job satisfaction: evidence from telecom sector of Pakistan", Pakistan Journal of Commerce and Social Sciences, Vol. 8 No. 1, pp. 149-169. 
15.Ozdemir, S. (2009), „Factors influnecing job satisfaction in Azerbaijan companies", Journal of Qafqaz University, Vol. 26, 103-108.

16.Pejic-Bach, M., Zoroja, J., Jirous, Z. (2013), „Croatian telecommunication market: Concentration trends in the period from 2003 to 2008", Interdisciplinary Description of Complex Systems, Vol. 11 No. 1, pp. 131-142.

17.Rahimic, Z., Podrug, N. (2013), „Medjunarodni menadzment" [International Management], Ekonomski fakultet Univerziteta u Sarajevu (School of Economics \& Business, University of Sarajevo).

18.Rahimic, Z. (2010), „Menadzment ljudskih resursa“, [HR Management] Ekonomski fakultet Univerziteta u Sarajevu (School of Economics \& Business, University of Sarajevo).

19.Santos-Vijande, M.L., Alvarez-Gonzalez, L.I. (2007), „Innovativeness and organizational innovation in total quality oriented firms: The moderating role of market turbulence", Technovation, Vol. 27 No. 9, pp. 514-532.

20.Scott, S.G., Bruce, R.A. (1994), „Determinants of innovative behavior: A path model of individual innovation in the workplace", Academy of Management Journal, Vol. 37 No. 3 , pp. 580-607.

21.Singh, M., Sarkar, A. (2013), "Dimensions, outcomes and mediating roles of empowerment", Management and Labour Studies, Vol. 38 No. 4, pp. 315-333.

22.Spreitzer, G.M., Kizilos, M.A., Nason, S.W. (1997), „A dimensional analysis of the relationship between psychological empowerment and effectiveness, satisfaction, and strain", Journal of Management, Vol. 23 No. 5, pp. 679-704.

23.Straiter, K.L. (2005), "The effects of supervisors' trust of subordinates and their organization on job satisfaction and organizational commitment", International Journal of Leadership Studies, Vol. 1 No. 1, pp. 86-101.

24.Tompenaars, F., Hampden-Turner, C. (1998), „Riding Waves of Culture“, McGraw Hill, NY.

25.Weeks, M.R. \& Thomason, S. (2011), „An explntory assessment of the linkages between HRM practices, absorptive aapacity \& innovation in outsourcing relatonships", International Journal of Innovation Management, Vol. 15 No. 2, pp. 303-334.

26.West, M.A., Altink, W.M.M. (1996), „Innovation at work: Individual, group, organizational, \& sociohistorical perspectives", European Journal of Work and Org. Psychology, Vol. 5 No. 1, pp. 3-11.

27.Yoon, M.H., Seo, J.H., Yoon, T.S. (2004), „Effects of contact employee supports on critical employee responses \& customer service evaluation", Journal of Services Marketing, Vol. 18 No. 5, pp. 395-412.

\section{About the authors}

Anes Hrnjic, MA is a Teaching Assistant at University of Sarajevo within Department of Management and Organization since 2013 and PhD student in the field of Business/Management at the same institution. Previously, he obtained his Bachelor of Science degree in Business Administration in the United Sates at Stillman College and Master degree at University of Sarajevo defending master thesis in the field of Customer Relationship Management. Past professional experience include internship at EPA in Brussels, Belgium and work in largest telecom company in Bosnia and Herzegovina. Author can be contacted at anes.hrnjic@efsa.unsa.ba

Irma Djidelija, MA is a Teaching Assistant at University Dzemal Bijedic in Mostar within Department of Quantitative Economy since 2014 and PhD student at University of Sarajevo. Previously, she obtained her Bachelor's degree at University Dzemal Bijedic in Mostar and Master degree within a joint program of the University of Sarajevo and University in Mostar defending master thesis in the field of Operations Research. Previous experience includes training in major telecommunications company in Bosnia and Herzegovina and a demonstrator experience at the University in Mostar. Author can be contacted at irma_djidelija@hotmail.com 